\title{
Advances in Pharmacoepidemiology \& Drug Safety
}

\section{Technology Transfer: End Point of Research Process}

\section{Patil JS*}

VT's Shivajirao S Jondhle College of Pharmacy, Asangaon, Thane, Mumbai, India

\section{Introduction}

Technology transfer (TT) is nothing but transferring the research outcomes from organization to another for future use and development of new medicinal products, educational tools, safety equipment, electronic devices, and health services required for public use. TT bridges between science, engineering, law and government agencies [1-3]. Drug discovery and development process of novel medicinal product depends on TT which is considered as essential and grave. This process gives clarity to product development laboratory about production and commercialization. In pharmaceutical industry TT is helpful in enhancing the quality, efficacy and safety of the product through standardized process of cost effective production [4,5]. TT can be viewed from the perception of research and development activities. The findings of research work in laboratories on small scale are needed to commercialized, and hence, TT is important for scale up the product on commercial base. TT is thus defined as the process begins with the invention in laboratory to product development phase and then to a commercial scale. The TT is said to be successful provided both receiving and transferring organizations effectively utilize it to promote their business.

\section{Reasons for TT}

Once technology has been developed by an organization and the said organization is not having a capacity to commercialize, making to transfer the technology to organization which can successfully utilize it to promote the business. The organization develops an advanced technology with necessary regulatory approvals and suffers with lack of marketing channels; the developer of the technology might have to collaborate with other organizations with marketing and distribution capability. Any research institute develops a technology and does not have commercial capability, has to collaborate with other organization to introduce the product into market. Even many a time the developer of the technology may face a difficulty in the middle of the process of technology development has to collaborate with other institute to complete the process. For example, a pharmaceutical product developer does not have enough knowledge and capability to carry out the clinical and regulatory phases may collaborate with other institute which is capable to do it and finally bring into the market [6].

\section{Stages of TT}

TT requires the collaboration of many individuals in making success the developed technology to bring into the commercial reality. A specimen formulation development process goes through many stages with better understanding of operational procedure used, both critical and non-critical operational parameters, production environment including equipment and availability of excipients which helps to scale up successfully. It is also essential to ensure the standards and quality of the final product as developed by research and development section before scale up. Before transferring the technology, there are many stages to complete the process of technology development. AT the beginning, research and development department prepare the design of procedure and identify the excipients required, for this many preliminary studies are to be carried out. The developed technology is transferred from research and development department to production

section with all information such as master formula card including all details of intended product and packaging process. The information also includes product specifications and standard test procedures. The next step is optimization of the operational procedures with proper validation studies followed by scale up for production. Pharmaceutical product development process in pharma sector starts from half to two kilogram batch which can be scaled up to $10 \mathrm{~kg}$ and then to $100 \mathrm{~kg}$ on a pilot scale. Production scale varied between $200 \mathrm{~kg}$ and $1000 \mathrm{~kg}$. Pharma TT comprises production of dosage forms in larger batches on larger equipment. Scape up is usually done on the knowledge that has been gained research scale and during the small scale production process in the laboratory.

\section{Conclusion}

Technology transfer in pharmaceutical industries involves action to transfer the information and technology to apprehend the quality of design and final product. Successful technology yield reproducible results in its routine operation once it is transferred to an organization which commercializes it. Technology transfer helps the pharmaceutical organizations to reduce the production cost with reduced risk and rate of failure, and hence, major pharmaceutical companies look for technology transfer opportunities.

\section{References}

1. Patil JS, Shete MB, Gurav PB, Chipde VD, Kulakarni RG (2013) Translation and Commercialization of Pharmaceutical Scientific Innovations: An Overview. J Adv Pharm Edu Res 3: 125-135.

2. E Domb, Mlodozeniec A (2004) Using TRIZ to Accelerate Technology Transfer in the Pharmaceutical Industry.

3. http://www.research.cornell.edu/cotab a.html

4. Reamer A, Icerman L, Youtie J (2003) Technology Transfer and Commercialization: Their Role in Economic Development.

5. DS Patel (2007) An overview for pharmaceutical industry. Int Biopharm Association publication 1-10.

6. Mahboudi M, Anthan BR (2010) Effective factors in Technology Transfer in pharmaceutical industries of Iran, A case study. The IUP J Knowledge Management 8: 98-110.

*Corresponding author: Patil JS, VT's Shivajirao S Jondhle College of Pharmacy, Asangaon, Thane, Mumbai, India, Tel: 09594962017; E-mail: pharmajspati@gmail.com

Received February 06, 2016; Accepted February 11, 2016; Published February 13, 2016

Citation: Patil JS (2016) Technology Transfer: End Point of Research Process. Adv Pharmacoepidemiol Drug Saf 5: e141. doi:10.4172/2167-1052.1000e141

Copyright: @ 2016 Patil JS. This is an open-access article distributed under the terms of the Creative Commons Attribution License, which permits unrestricted use, distribution, and reproduction in any medium, provided the original author and source are credited. 